\title{
Preliminary study of an intense rainfall episode in Corsica, 14 September 2006
}

\author{
D. Lambert and S. Argence \\ Laboratoire d'Aérologie, CNRS-UPS, Toulouse, France
}

Received: 2 September 2007 - Revised: 4 December 2007 - Accepted: 28 January 2008 - Published: 9 April 2008

\begin{abstract}
A preliminary study of the 14 September 2006 heavy rainfall episode in Corsica is presented. Two sets of initial and coupling fields were used to run the French non-hydrostatic mesoscale model, MESO-NH. Three interactive 2-way nested domains were used, having $150 \times 120$, $150 \times 150$ and $125 \times 200$ grid points and $50 \mathrm{~km}, 10 \mathrm{~km}$ and $2 \mathrm{~km}$ mesh sizes. 50 vertical levels were defined. From ground level to $2000 \mathrm{~m}$, the vertical resolution was $60 \mathrm{~m}$, whereas it was $600 \mathrm{~m}$ above. Convection was parameterized for the coarser and intermediate domains and assumed to be explicitly resolved for the $2 \mathrm{~km}$ grid. At large scale, the situation is well represented by both simulations but, at the fine scale, they present significant differences. Comparison with the observations did not allow the two simulations to be discriminated. Even though the main high-level dynamical ingredients usually associated with rain storms were present in both simulations, their fine scale evolution was not reproduced well. Near the surface, there were significant differences between the two simulations. Vertical motion fields associated with convective phenomena were different in the innermost domain. A cold pool acting as a warm front off the east coast was associated with the main rainfall area over the sea in one simulation whereas in the second one, it seemed that the Corsican mountains acted as a barrier, leading to inland rainfall. This preliminary study gives perspectives for future sensitivity tests. For example, an investigation is planned of the influence of the high level dynamics, the SST and a better description of the orography.
\end{abstract}

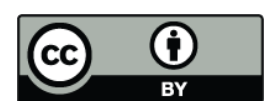

Correspondence to: D. Lambert (dominique.lambert@aero.obs-mip.fr)

\section{Introduction}

Flooding is, along with windstorms, one of the most devastating natural hazards in terms of loss of human life. The Mediterranean climate, usually pleasant with sunshine and fine weather, can sometimes present intense rainfall events on a variety of space and time scales. The Mediterranean Basin is known to have one of the highest concentrations of cyclones in the world (Pettersen, 1956). In particular, the Gulf of Genoa is the area where the concentration of cyclones is maximal.

In the last few years, several high-precipitation events have been listed around the western Mediterranean Basin, in Spain, Italy, Algeria and France, among others. For example, in November 2001, a storm flood in Algiers caused 886 lives to be lost (Argence et al., 2006).

The main synoptic ingredients leading to such heavy rainstorms are well known: in most cases, these two main ingredients are an upper tropospheric trough and a low level supply of warm, wet air. In spite of this knowledge and of recent improvements in operational forecasting, numerical weather predictions regularly fail to reproduce the intensity and distribution of precipitation of heavy rainstorms at the mesoscale.

Local weather forecasters still have difficulties in predicting such precipitation events, particularly over the sea near high relief. In this context, preliminary results are presented for the 14 September 2006 flood in Corsica. Section 2 provides a brief description of the meteorological situation. In Sect. 3, two MESO-NH simulations are analyzed to obtain a better interpretation at the finest scale. Conclusions and perspectives for future work are given in the final section.

\section{Description of the case study}

Corsica is located in the middle of the western Mediterranean basin. It is a "mountain surrounded by the sea". The altitude 


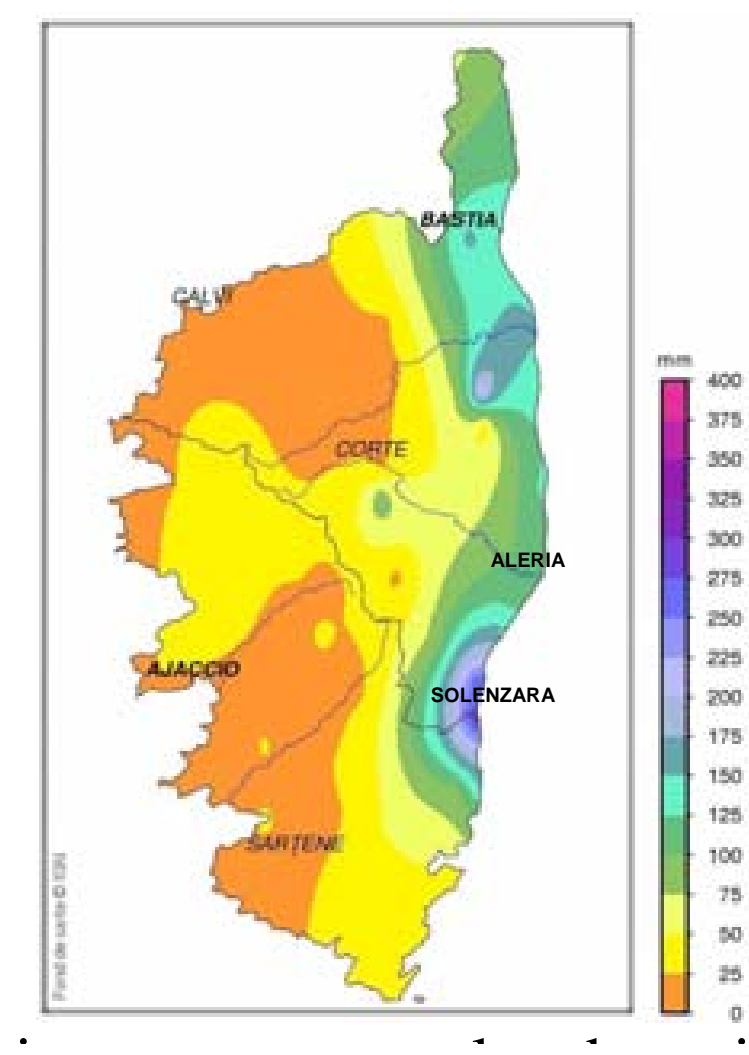

Fig. 1. Rain-gauge accumulated precipitation (mm) from 14 September 06:00 UTC to 15 September 06:00 UTC. (Courtesy of DIR Sud-Est - Météo-France).

is $2710 \mathrm{~m}$ at its highest point and there are twenty other mountains tops higher than $2000 \mathrm{~m}$. The average altitude is $568 \mathrm{~m}$. Corsica has the highest mountains and the largest number of rivers than any Mediterranean island; $180 \mathrm{~km}$ long, $80 \mathrm{~km}$ wide, the mountain range runs roughly from north-west to south-east.

On 14 September 2006, a heavy rainfall episode reached the eastern part of the island with accumulated precipitation of more than $400 \mathrm{~mm}$, which caused impressive material damage. The road network was cut and hundreds of people were evacuated. Figure 1 shows the 24-h accumulated precipitation from 06:00 UTC 14 September to 06:00 UTC 15 September, obtained from the Météo-France rain gauge network. This figure shows that it was mainly the eastern coast of the Island that was affected by the rain storm, with values around $150 \mathrm{~mm}$ except for the extreme south. The maximum value was located at Solenzara.

At 00:00 UTC 14 September, the meteorological synoptic situation was characterized by an upper level trough extending from the North Atlantic to the south of Spain (Fig. 2). This structure was related to a stratospheric intrusion in the troposphere and characterized by low altitudes of the $1.5 \mathrm{pvu}^{1}$ surface (Fig. 2).

\footnotetext{
${ }^{1}$ Potential Vorticity Unit $\left(1 \mathrm{pvu}=10^{-6} \mathrm{~m}^{2} \mathrm{~s}^{-1} \mathrm{~K} \mathrm{~kg}^{-1}\right)$
}

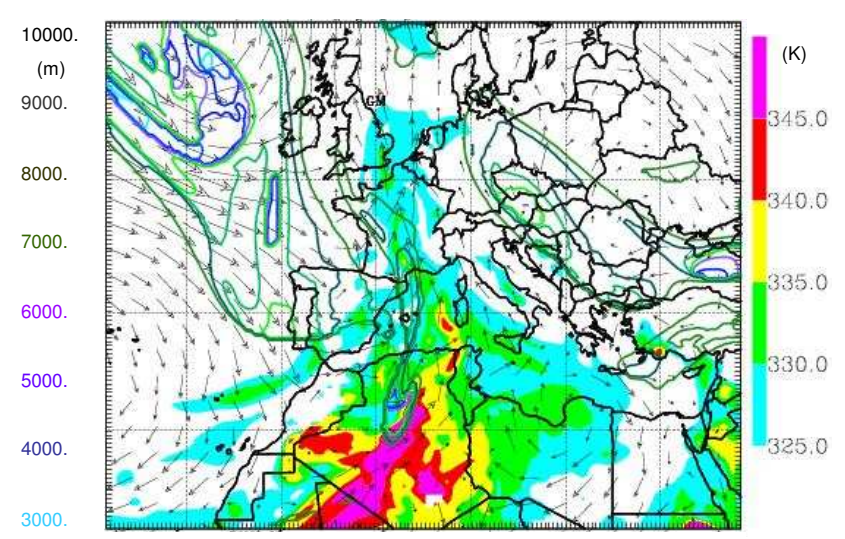

Fig. 2. ARPEGE analysis for 14 September 00:00 UTC: $850 \mathrm{hPa}$ equivalent potential temperature $(\mathrm{K}), 850 \mathrm{hPa}$ wind arrows and altitude of the $1.5 \mathrm{pvu}$ surface (isolines, $\mathrm{m}$ ).

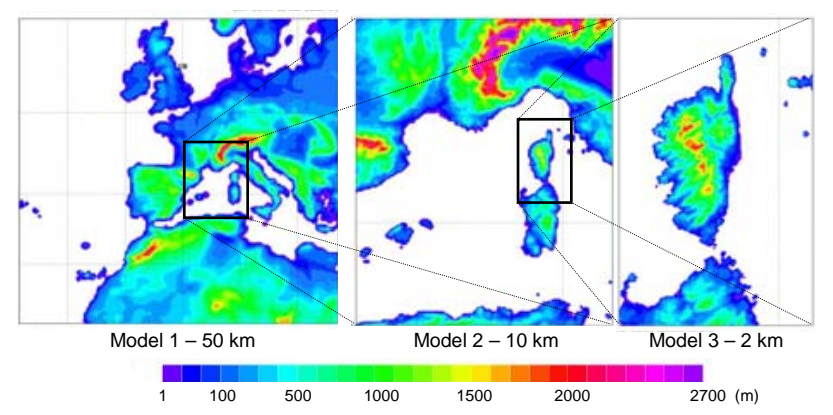

Fig. 3. Simulation domains with topography.

Downstream of this main trough, an elongated Potential Vorticity (PV) filament extended from southern England to Algeria. At low levels, air masses were advected from Africa to the north of the western part of the Mediterranean Basin. They were warm and wet, as shown by high $850 \mathrm{hPa}$ equivalent potential temperature values. From the synoptic analysis, it was found that a rainy episode was more than likely but the difficulty was to specify the place and the time.

\section{Initial and coupling analyses sensitivity on two meso- nh simulations}

Two sets of initial and coupling fields $\left(E^{2} \mathrm{EMWF}^{2}\right.$ and ARPEGE $^{3}$ analyses) were used to run the French MESONH model (Lafore et al., 1998) starting from 12:00 UTC 13 September and integrating over $36 \mathrm{~h}$. The model was used with three two-way nested domains of 50,10 and $2 \mathrm{~km}$ grid spacing (Fig. 3), called model1, model 2 and model3, respectively. Model 3 allowed the island top, at $2180 \mathrm{~m}$, to be represented. It was characterized by an explicit description of the convection.

\footnotetext{
${ }^{2}$ European Centre for Medium range Weather Forcasting

3 Action de Recherche Petite Echelle Grande Echelle, from Météo-France
} 


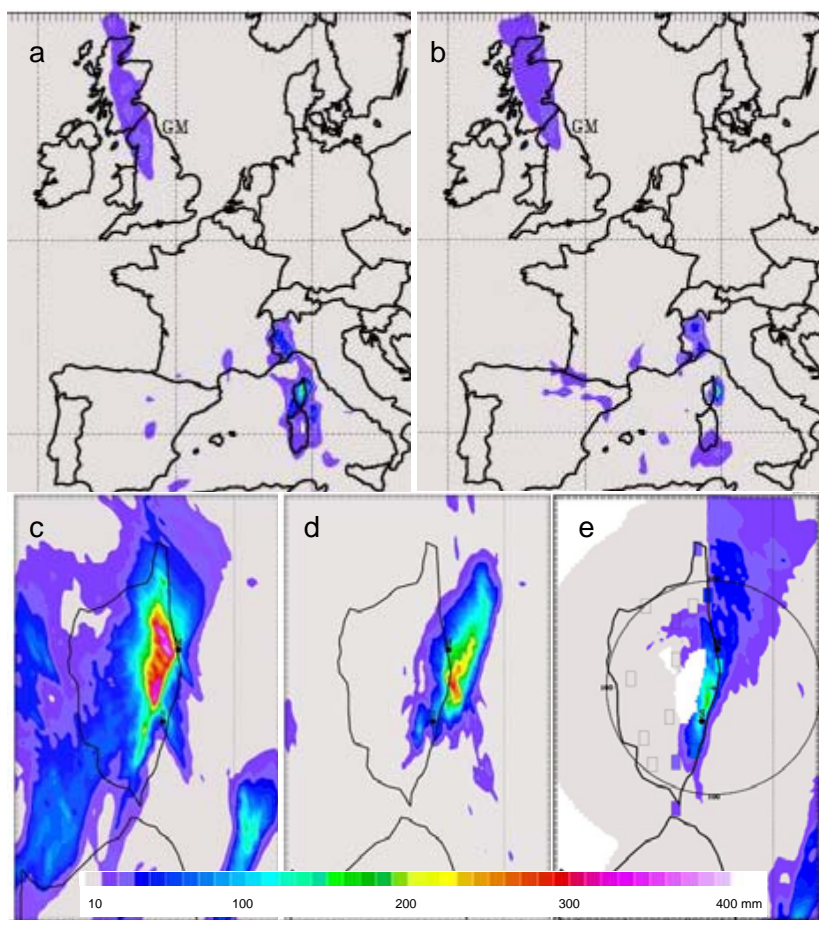

Fig. 4. Accumulated precipitation (mm) from 14 September 06:00 UTC to 12:00 UTC. (a, b) are blow-ups in model1, (c, d) are for model 3 and (e) is for radar (Météo France / DSO / CMR) and rain-gauge data (small squares). (a, c) are for E1 simulations, (b, d) are for E2 simulations. GM stands for Greenwich meridian.

Figure 4 displays the results of these two simulations in terms of 6-h accumulated rainfall from 14 September 06:00 UTC to 12:00 UTC for blow-ups in model1 (Fig. 4a, b) and model 3 (Fig. 4c, d). The MESO-NH simulation coupled with ECMWF is denoted as E1 and that coupled with ARPEGE as E2. Both simulations reproduce the rain episode. For model1, E1 and E2 show great similarities. There are two main precipitation areas, one located over the north of Great-Britain and the other from Sardinia to the French-Italian border. During these $6 \mathrm{~h}$, the maximum values are located over Corsica. They are $159 \mathrm{~mm}$ and $166 \mathrm{~mm}$ for $\mathrm{E} 1$ and E2, respectively. For model3, E1 and E2 are very different in localization and intensity. The maximum value of $\mathrm{E} 1$ is $394 \mathrm{~mm}$ whereas it is $318 \mathrm{~mm}$ for E2. Moreover, most of the precipitation is located inland for E1 and over the sea for E2. Figure 4e displays precipitation given by the radar located in Aléria (see Fig. 1) and rain gauge data. These observational data lead to more confidence in E1 for the localization (inland) and in E2 for the intensity. Note that the 6-12-h interval was chosen because radar data were not available for the entire episode.

What are the reasons for such differences? The high-level dynamics were investigated first. Figure 5 shows the brightness temperature of the Meteosat Second Generation water vapour (MSGWV) image superimposed with the $1.5 \mathrm{pvu}$

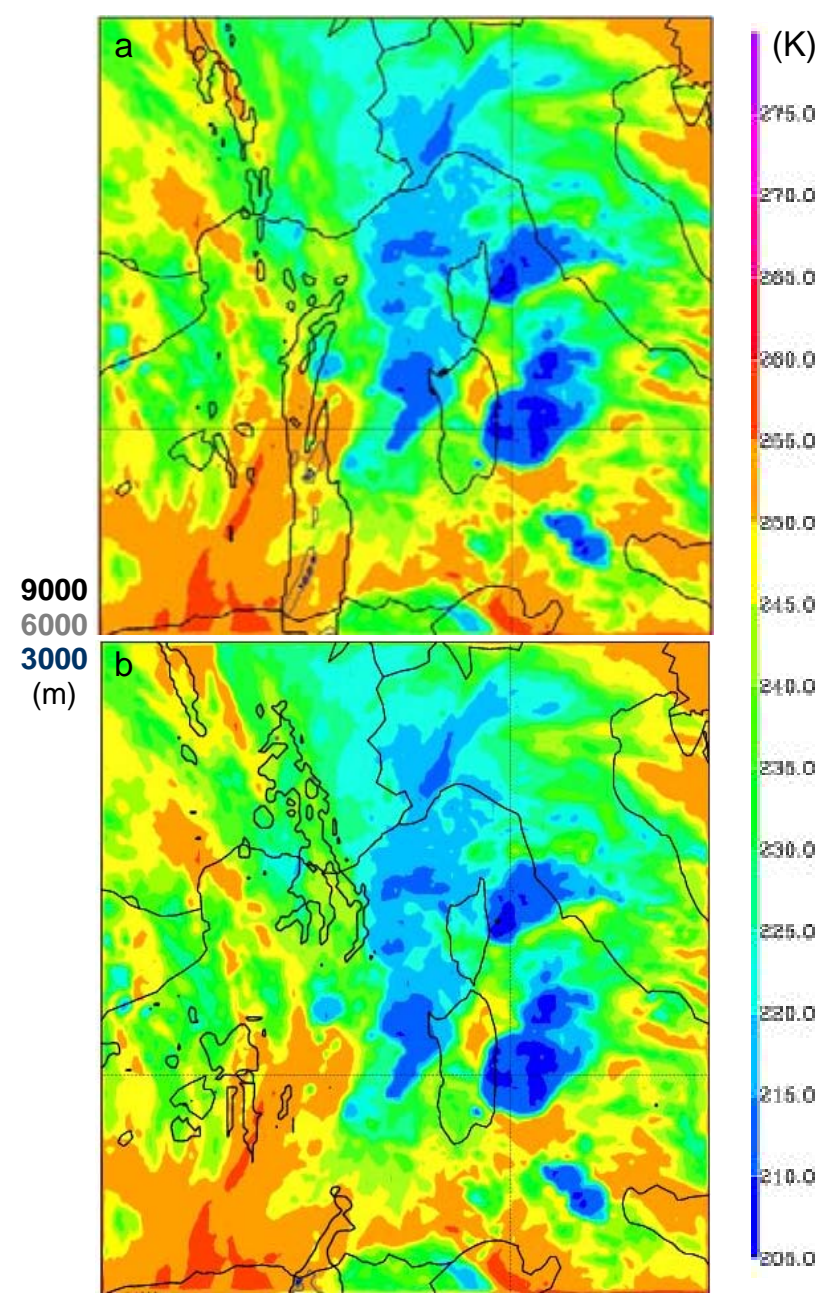

Fig. 5. Altitude of the 1.5 pvu surface (isolines, m) and MSG water vapour brightness temperature $(\mathrm{K})$ for 14 September 06:00 UTC for E1 (a) and E2 (b).

altitude of E1 (Fig. 5a) and E2 (Fig. 5b) on model2 for 06:00 UTC 14 September. The high level PV structure is different in E1 and E2. None of the simulations is in agreement with the MSGWV image, for which high PV values for high brightness temperatures were expected. On model2, E1 gives a north-south elongated structure over the sea with maximum values in the southern part whereas E2 gives a small PV structure over the south of France. As a consequence, the high level dynamics were different in E1 and E2 (not shown).

The dynamics near the surface will now be investigated. Figure 6 displays the wind at $10 \mathrm{~m}$ high for E1 and E2 at 09:00 UTC 14 September. The two simulations are in agreement for the wind direction, with the surface wind blowing from the south-east. However, they are different in intensity off the east coast. E1 is more intense than E2; E2 exhibits a very low-wind area off the north-east coast. This area corresponds to a cooling as shown in Fig. $7 \mathrm{~b}$. 

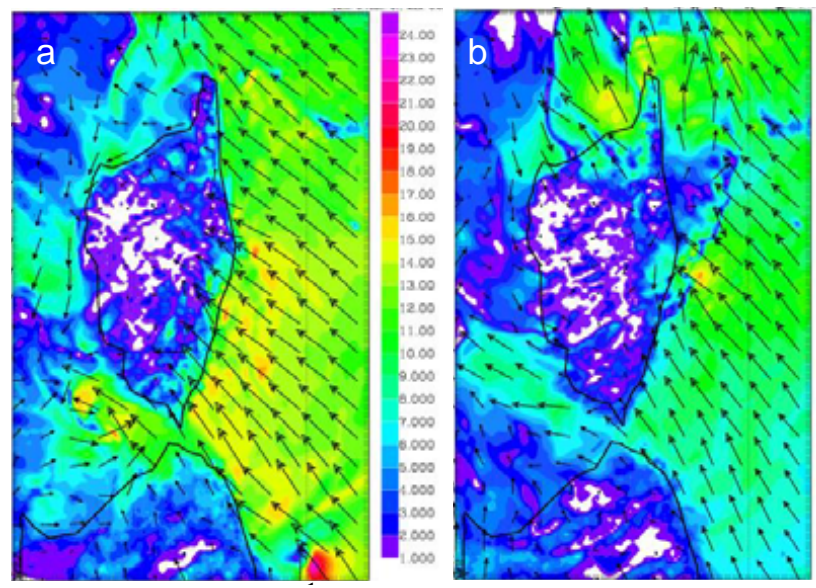

Fig. 6. Wind $\left(\mathrm{ms}^{-1}\right)$ at $10 \mathrm{~m}$ high for 14 September 09:00 UTC for E1 (a) and E2 (b).

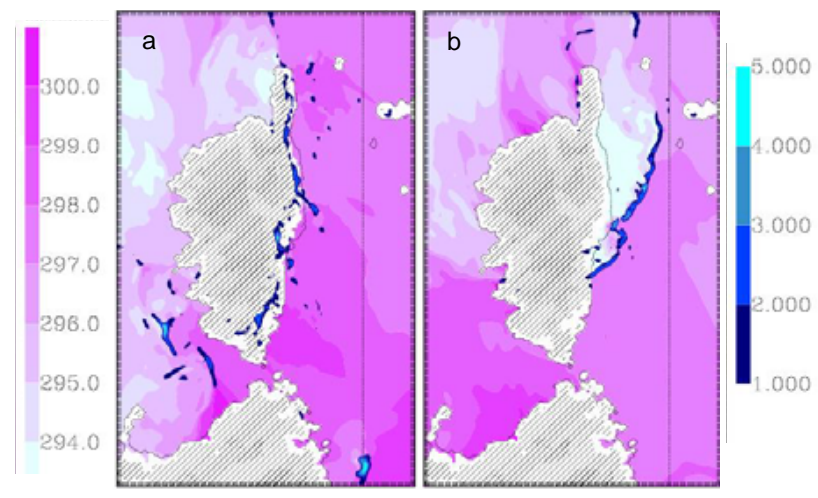

Fig. 7. $50 \mathrm{~m}$ high virtual potential temperature (purple shading, $\mathrm{K}$ ) and $500 \mathrm{~m}$ high vertical velocity (blue, $\mathrm{ms}^{-1}$ ) for 14 September 09:00 UTC for E1 (a) and E2 (b).

This cooling can be associated with the extension of the cloud coverage off the east coast as already mentioned (Fig. 4d). In their study, Nuissier et al. (2007) mention this phenomenon, called a low level cold pool. The cold pool acts as a warm front characterized by ascending motion off the east coast in E2 (Fig. 7b). In contrast, this cold pool is not present in E1 and the upward vertical velocity is associated, in this case, with the mountains acting as a barrier.

\section{Conclusion and outlook}

A preliminary study of the 14 September 2006 heavy rainfall episode in Corsica has been presented. Two initial and coupling field sets were used to run the MESO-NH model. The situation is well reproduced by both simulations at large scale whereas, at fine scale, there are significant differences between the simulations. Comparison with the observations does not allow the two simulations to be discriminated. Al-

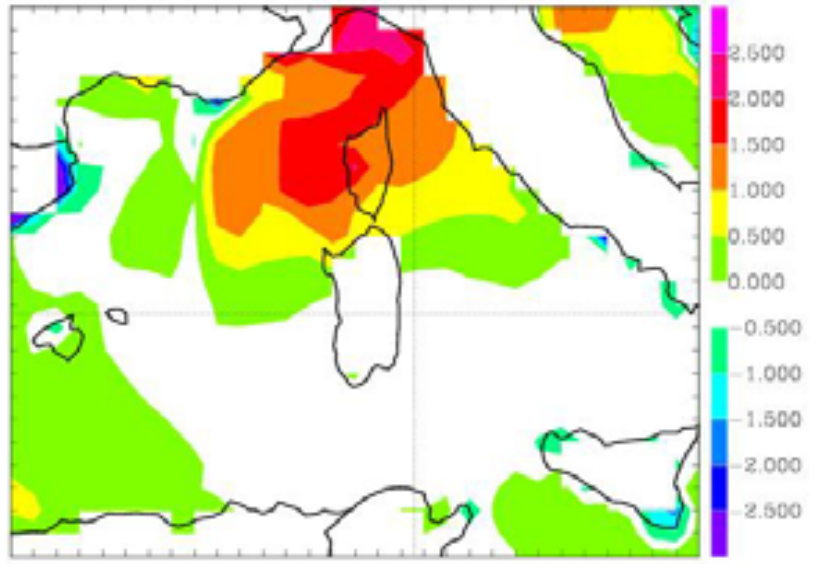

Fig. 8. SST difference (K) between ECMWF and ARPEGE analyses for 13 September 2006.

though the main high level dynamic ingredients usually associated with rain storms are present in both simulations, their fine scale evolution is not well reproduced. It can be hypothesized that the accuracy of the high level analyses is not good enough. Sensitivity tests using a PV inversion tool (Chaigne and Arbogast, 2000; Lambert et al., 2004) will be performed to bring the high level analyses closer to the real state of the atmosphere. This expected improvement should lead to a better understanding of the processes at lower levels. As a result, it should discriminate between the orographic forcing suggested to explain the simulation E1 and the low level cold pool suggested for E2.

These high altitude sensitivity tests on the dynamics will only be valuable if they are not distorted by the surface conditions. Figure 8 shows the sea surface temperature (SST) difference between ECMWF and ARPEGE analyses for the 13 September 2006. The Gulf of Genoa is characterized by an SST difference of up to 2.5 degrees. Although Lebaupin et al. (2006) have shown that it is more the averaged SST than the presence of anomalies which impacts on the forecast of such precipitation events, sensitivity tests on the SST will be performed.

Once high altitude and surface conditions have been refined, the influence of a better description of the orography on local wind fields and on rainfall will be tested. This study is underway in the framework of the future HYdrological cycle in the Mediterranean EXperiment (HYMEX http://www.cnrm.meteo.fr/hymex/). 
Acknowledgements. We wish to thank P. Tabary and C. Guéguen (Météo-France, DSO/CMR) for providing the radar data and V. Jacq (Météo-France, DIR SE) for the rain-gauge data.

Edited by: S. C. Michaelides

Reviewed by: two anonymous referees

\section{References}

Argence, S., Lambert, D., Richard, E., Söhne, N., Chaboureau, J.P., Crépin, F., and Arbogast, P.: High resolution numerical study of the Algiers 2001 flash flood: sensitivity to the upper-level potential vorticity anomaly, Adv. Geosci., 7, 251-257, 2006, http://www.adv-geosci.net/7/251/2006/.

Chaigne, E. and Arbogast, P.: Multiple potential vorticity inversions in two FASTEX cyclones, Q. J. R. Meteorol. Soc., 126, 1711$1734,2000$.
Lafore, J.-P., Stein, J., Bougeault, P., Ducrocq, V., Duron, J., Fisher, C., Hereil, P., Mascart, P., Masson, V., Pinty, J.-P., Redelsperger, J.-L., Richard, E., and Vila-Guerau de Arellano, J.: The Meso$\mathrm{NH}$ atmospheric simulation system. Part I: adiabatic formulation and control simulations, Ann. Geophys., 16, 90-109, 1998, http://www.ann-geophys.net/16/90/1998/.

Lambert, D., Arbogast, P., Cammas, J.-P., Donnadille, J., and Mascart, P.: A cold air cyclogenesis study using potential vorticity inversion method, Q. J. R. Meteorol. Soc., 130, 2953-2970, 2004.

Lebeaupin, C., Ducrocq, V., and Giordani, H.: Sensitivity of torrential rain events to the sea surface temperature based on highresolution numerical forecasts, J. Geophys. Res., 111, D12110, doi:10.1029/2005JD006541, 2006.

Nuissier, O., Ducrocq, V., Ricard, D., Lebeaupin, C., and Anquetin, S.: A numerical study of three catastrophic precipitating events over Southern France, Part I: Numerical framework and synoptic ingredients, Q. J. R. Meteorol. Soc., in press, 2007.

Pettersen, S.: Weather analysis and forecasting, McGraw-Hill, New-York, 428 pp., 1956. 